\title{
Surfactant Proteins A and D - New Diagnostic and Prognostic Biomarkers of Acute Respiratory Distress Syndrome in Septic Patients \\ Kuzovlev AN
}

V.A. Negovsky Scientific Research Institute of General Reanimatology RAMS, Moscow, Russia

Acute Respiratory Distress Syndrome (ARDS) is a noncardiogenic pulmonary edema, in the basis of which lies an alteration (dystrophy, necrosis, apoptosis) of alveolar epithelium, pulmonary microcirculation endothelium, and their basal membranes (including structures of aerohematic barrier) by endogenous and exogenous aggressive factors, leading to a vascular permeability growth and development of acute respiratory failure [1-3].

A multicenter investigation at the V.A. Negovsky scientific research institute of general reanimatology in 2000-2011 confirmed that the noncardiogenic pulmonary edema is the crucial element of the pathogenesis of early ARDS stage and a key for its detection in the clinical setting. The modern approach of ARDS early diagnosis was developed at the V.A. Negovsky scientific research institute of general reanimatology. These criteria provided clinicians with a possibility to diagnose an early, reversible stage of $A R D S$, start prompt treatment, decrease the duration of artificial pulmonary ventilation by 4-7 days, the intensive care unit stay by 5-6 days, the hospital stay by 10 days, the rate of pulmonary complications by $31,9 \%$ and the mortality - by $29,6 \%$ [1-4].

But this diagnostic approach does not provide us with a possibility to detect the injury of the alveolar epithelium. Biomarkers of the alveolar epithelium injury give an enormous prospect in the field of ARDS early diagnosis, prognosis and monitoring of the treatment efficacy [5].

Clinical investigations at the V.A. Negovsky scientific research institute of general reanimatology in 2012-2013 have confirmed that plasma surfactant proteins A (SP-A) and D (SP-D) may be used as biomarkers of ARDS in septic patients with severe intrabdominal surgical infections [6].

Plasma SP-D is a sensitive and specific diagnostic biomarker of ARDS and its early stages in septic patients. Plasma SP-D levels are significantly higher in patients with ARDS, than in patients without ARDS and have a good diagnostic capacity for the ARDS (any stage): SP-D on the day of sepsis diagnosis $\geq 115,8 \mathrm{ng} / \mathrm{ml}$ yields a sensitivity of $82,5 \%$ and specificity of $80,0 \%$ (AUC 0,$87 ; 95 \%$ CI $0,778-0,984$; $=0,0026$ ) for the diagnosis of ARDS (any stage). Moreover, plasma SP-D is significantly higher in patients with the $2^{\text {nd }}$ stage of ARDS than in patients with the $1^{\text {st }}$ stage of ARDS (day $0-154,6 \pm 125,2 \mathrm{ng} / \mathrm{ml}$ vs. $451,8 \pm 299,2 \mathrm{ng} / \mathrm{ml}$; day $3-129,3 \pm 74,9 \mathrm{ng} / \mathrm{ml}$ vs. $362,9 \pm 202,0 \mathrm{ng} /$ $\mathrm{ml}$; day $5-167,8 \pm 120,4 \mathrm{ng} / \mathrm{ml}$ vs. $428,5 \pm 372,4 \mathrm{ng} / \mathrm{ml}$; day $7-186,2 \pm$ $127,1 \mathrm{ng} / \mathrm{ml}$ vs. $415,5 \pm 337,0 \mathrm{ng} / \mathrm{ml}$ ). Plasma SP-D on the day of sepsis diagnosis $\leq 253,0 \mathrm{ng} / \mathrm{ml}$ yields a sensitivity of $90,0 \%$ and specificity of $74,0 \%$ (AUC 0,$83 ; 95 \%$ CI $0,631-0,951 ; p=0,0001$ ) for the diagnosis of the $1^{\text {st }}$ stage of ARDS [6].

Plasma SP-A is a sensitive and specific prognostic biomarker of ARDS in septic patients. Plasma SP-A is significantly higher in patients who died of ARDS. Plasma SP-A has a good prognostic capacity for the lethal outcome in ARDS patients: SP-A on the day of sepsis diagnosis $\geq 38,8 \mathrm{ng} / \mathrm{ml}$ yields a sensitivity of $65,0 \%$ and a specificity of $80,0 \%$ (AUC 0,$74 ; 95 \%$ CI 0,577-0,866; $\mathrm{p}=0,0026$ ). Plasma SP-A on the day of sepsis diagnosis has a good prognostic capacity for the development of ARDS on days 4-5 in septic patients: SP-A on day $1 \geq 24,5 \mathrm{ng} / \mathrm{ml}$ yields a sensitivity of $60,0 \%$ and a specificity of $85,0 \%$ (AUC 0,$74 ; 95 \%$ CI $0,527-0,871 ; \mathrm{p}=0,0034)$.

Therefore, plasma surfactant proteins are sensitive and specific diagnostic and prognostic biomarkers of ARDS. There research data should be implemented into the daily clinical practice, which will provide us with an early ARDS diagnosis, a more prompt and effective treatment and outcomes improvement. Our future research will be focused on the investigations into other candidate biomarkers of ARDS and severe infections (Clara cell protein, bacterial permeability increasing protein, neutrophil elastase, etc.).

\section{References}

1. Moroz V, Goloubev A, Kuzovlev AN (2010) Acute respiratory distress syndrome: new classification. Semin Cardiothorac Vasc Anesth 14: 46.

2. Moroz VV, Goloubev (2007) Classification of acute respiratory distress-syndrome. General Reanimatology III (5-6): 7-9.

3. Moroz VV, Goloubev (2006) Principles of early stages of acute lung injury diagnosis. General Reanimatology II 4: 5-7.

4. Kuzovlev AN, Moroz VV, Goloubev AM, Polovnikov SG (2010) Diagnosis of acute respiratory distress syndrome in nosocomial pneumonia. Semin Cardiothorac Vasc Anesth 14: 231-241.

5. Proudfoot AG, Hind M, Griffiths MJ (2011) Biomarkers of acute lung injury: worth their salt? BMC Med 9: 132.

6. Kuzovlev AN, Moroz VV, Goloubev AM, Polovnikov SG (2013) Biomarkers for early stage of acute respiratory distress syndrome in septic patients: surfactant protein D and Clara cell protein. Crit. Care 17 (Suppl. 2): 100.
*Corresponding author: Kuzovlev AN, V.A. Negovsky Scientific Research Institute of General Reanimatology RAMS, Moscow, Russ +ia, E-mail: artem_kuzovlev@mail.ru

Received April 29, 2013; Accepted May 02, 2013; Published May 06, 2013

Citation: Kuzovlev AN (2013) Surfactant Proteins A and D - New Diagnostic and Prognostic Biomarkers of Acute Respiratory Distress Syndrome in Septic Patients. J Pulm Respir Med S12: e001. doi:10.4172/2161-105X.S12-e001

Copyright: ( 2012 Kuzovlev AN. This is an open-access article distributed under the terms of the Creative Commons Attribution License, which permits unrestricted use, distribution, and reproduction in any medium, provided the original author and source are credited. 